\title{
Becoming an Effective Clinician for People Who Stutter: What Do You Need to Know?
}

Stuttering is a disorder that can have a profound effect on a speaker's ability to communicate effectively and participate in educational, vocational, and social activities. ${ }^{1-6}$ Unfortunately, numerous studies over many years have documented the fact that many speech-language pathologists are not comfortable working with individuals who stutter. ${ }^{7-9}$ The result is that many people who stutter receive inadequate treatment, and this, in turn, may leave them feeling less able to overcome the challenges associated with their communication difficulties. ${ }^{10-13}$

Fortunately, there is much that can be done to change this situation; clinicians can develop the skills they need to effectively treat individuals who stutter. ${ }^{14}$ Although the field's documentation of stuttering treatment efficacy is far from adequate, it is clear that effective treatment can help people increase their speech fluency and minimize the adverse impact of stuttering for people who live with this potentially debilitating disorder. ${ }^{15-19}$ Helping clinicians work toward this critical outcome is the goal of this issue of Seminars in Speech and Language.

Specifically, this issue provides clinicians with background knowledge they need to help people of all ages who stutter to overcome the burden of stuttering. The issue is presented in two sections. The first focuses on helping clinicians develop a better understanding of the stuttering disorder and what can be accomplished through treatment; the second provides more specific detail about stuttering treatment for preschool children and their families, schoolaged children, and adolescents and adults.

Note that the goal of the first section is not to describe theories of stuttering, but rather to help clinicians develop a better awareness of the experiences and perspectives of individuals who stutter-and, just as importantly, to help clinicians understand the valuable role they can play in the therapeutic process. Thus, in the first article, Manning discusses the nature of clinically meaningful change in stuttering treatment and reviews the factors that contribute to successful intervention. In the second article, Quesal emphasizes the importance of the clinician's role in successful treatment by highlighting the necessity for clinicians to develop a deeper sense of empathy for individuals who stutter. In the third article, Healey explores one of the many reasons such empathy is neededthat is, the negative reactions that listeners commonly exhibit in response to stuttered speech. Finally, the first section concludes with an article by Bernstein Ratner discusses current research about stuttering, for effective evaluation and treatment strategies should always be based upon current scientific knowledge.

The second section then builds upon this foundation by providing suggestions for how clinicians can provide effective treatment for individuals in different age groups who stutter. Specifically, Millard and Cook review a parent-and-child treatment program for preschool children who stutter; Yaruss describes a comprehensive set of treatment strategies for school-aged children; and Blomgren discussed
${ }^{1}$ Communication Science and Disorders, University of Pittsburgh, Pittsburgh, Pennsylvania.

Address for correspondence and reprint requests: J. Scott Yaruss, Ph.D., Communication Science and Disorders, University of Pittsburgh, 4033 Forbes Tower, Pittsburgh, PA 15260 (e-mail: jsyaruss@pitt.edu).

Stuttering Treatment: Becoming an Effective Clinician;
Guest Editor, J. Scott. Yaruss, Ph.D.

Semin Speech Lang 2010;31:205-206. Copyright (C) 2010 by Thieme Medical Publishers, Inc., 333 Seventh Avenue, New York, NY 10001, USA. Tel: +1(212) 5844662.

DOI: http://dx.doi.org/10.1055/s-0030-1265753.

ISSN 0734-0478. 
treatment for adolescents and adults who stutter. The issue concludes with a synopsis and synthesis, which highlights key "takehome" messages that readers can use to support their ongoing professional development as they become effective clinicians for people who stutter.

Of course, a single issue of a journal cannot hope to provide all of the information clinicians need to become superior clinicians for a given disorder. It can, however, provide a solid foundation about the disorder and point clinicians along the path they can follow to become more effective practitioners. It is hoped that readers of this issue will find an invitation to follow such a path and that, by studying the information presented herein, they will find themselves better equipped to help individuals who stutter.

\section{J. Scott Yaruss, Ph.D. ${ }^{1}$ Guest Editor}

\section{REFERENCES}

1. Cooper EB. Chronic perseverative stuttering syndrome: a harmful or helpful construct? Am J Speech Lang Pathol 1993;2:11-15

2. Gabel RM, Blood GW, Tellis GM, Althouse MT. Measuring role entrapment of people who stutter. J Fluency Disord 2004;29(1):27-49

3. Klein JF, Hood SB. The impact of stuttering on employment opportunities and job performance. J Fluency Disord 2004;29(4):255-273

4. Klompas M, Ross E. Life experiences of people who stutter, and the perceived impact of stuttering on quality of life: personal accounts of South African individuals. J Fluency Disord 2004;29(4): 275-305

5. Murphy W. A preliminary look at shame, guilt, and stuttering. In Bernstein Ratner N, Healey EC, eds. Stuttering Research and Practice: Bridging the Gap. Mahwah, NJ: Lawrence Erlbaum; 1999: 131-143
6. Yaruss JS, Quesal RW. Stuttering and the International Classification of Functioning, Disability, and Health: an update. J Commun Disord 2004;37(1):35-52

7. Brisk DJ, Healey EC, Hux KA. Clinicians' training and confidence associated with treating school-age children who stutter: a national survey. Lang Speech Hear Serv Sch 1997;28:164-176

8. Cooper E, Cooper C. Clinician attitudes toward stuttering: two decades of change. J Fluency Disord 1996;21:119-136

9. St. Louis KO, Lass NJ. A survey of communication disorders students' attitudes toward stuttering. J Fluency Disord 1981;6:49-79

10. Ahlbach J, Benson V, eds. To Say What Is Ours. Anaheim Hills, CA: National Stuttering Project; 1994

11. Hood S, ed. Advice to Those Who Stutter. 2nd ed. Memphis, TN: Stuttering Foundation of America; 1998

12. St. Louis K. Living with Stuttering. Morgantown, WV: Populore Publishing; 2001

13. Yaruss JS, Quesal RW, Reeves L, et al. Speech treatment and support group experiences of people who participate in the National Stuttering Association. J Fluency Disord 2002;27(2):115-133; quiz 133-134

14. Manning W. Clinical Decision Making in Fluency Disorders. 3rd ed. Clifton Park, NY: Cengage Learning; 2010

15. Andrews G, Guitar B, Howie P. Meta-analysis of the effects of stuttering treatment. J Speech Hear Disord 1980;45(3):287-307

16. Bloodstein O, Bernstein Ratner N. A Handbook on Stuttering. 6th ed. Clifton Park, NY: Thomson/ Delmar Learning; 2008

17. Bothe AK, Davidow JH, Bramlett RE, Ingham RJ. Stuttering treatment research 1970-2005: I. Systematic review incorporating trial quality assessment of behavioral, cognitive, and related approaches. Am J Speech Lang Pathol 2006; 15(4):321-341

18. Prins D, Ingham RJ. Evidence-based treatment and stuttering-historical perspective. J Speech Lang Hear Res 2009;52(1):254-263

19. Thomas C, Howell P. Assessing efficacy of stuttering treatments. J Fluency Disord 2001; 26(4):311-333 